Bulgarian Academy of Sciences. Space Research and Technology Institute.

Aerospace Research in Bulgaria. 32, 2020, Sofia

DOI: https://doi.org/10.3897/arb.v32.e07

\title{
AIRCRAFT NOISE LEVEL CALCULATION DURING TAKE-OFF
}

\author{
Hristina Georgieva \\ Mechanical Department - Technical University of Sofia \\ e-mail: hgeorgieva@tu-sofia.bg
}

\begin{abstract}
Keywords: Aircraft Trajectory, Departure, Modeling, Aircraft Noise, Calculation, Aperational Parameters

Abstract

A mathematical model with 4 degree of freedom created in Matlab for aircraft departure trajectory is described in this article. As a reference aircraft a midsize commercial passenger aircraft similar to an Airbus A320 has been chosen. The aircraft is represented by the rigid body and the parameters of model are collected from Airbus and the simulated departure trajectory at the Munich airport is based on a Standard Instrumental Departure. A semi-empirical model of Stone for predicting the jet noise has been used. The proposed model is validated against 10 real flights obtained from aircraft noise and flight track monitoring system at Munich airport. The computed error between the real data and modelling is reported on. Obtained results are presented numerical and graphically. The observed effects of flight operational parameters affecting the aircraft noise emission level during take-off represent subjects of discussions in the paper.
\end{abstract}

\section{Introduction}

The air transport has risen in the recent years due to the steadily growing number of passengers. As aircraft operations continue to grow as the average size at the most congested airports increases, communities have become highly sensitive to aircraft noise and their environmental impact. Aircraft noise is considered to be one of the most significant environmental problem concerns the local communities of modern cities, affecting mostly people living near airports, the passengers on the airport and people worked on the airport. The aircraft noise causes sleep disturbance, general annoyance, children impairment and cardiovascular diseases. Aircrft can be considered as a complex set of noise sources. Especially during the take-off, the engine plays the main role because the thrust level is maximum, which generally causes the highest noise levels on the ground. Due to technological improvements the significant progress has been made in terms of reduction of aircraft noise. But the growing amount of air traffic in Europe shows that an important part of the population is still exposed to problematic noise levels. According to the European Aviation Environmental 
Report for 2019 in the European Union (EU), aircraft noise is the third biggest source of noise exposure after road and rail traffic [1]. This is a critical issue that affects the sustainability of commercial aviation.

The aircraft noise depends on many different factors and it's very complex to control it. Significant research is currently being undertaken with the goal of reducing aircraft noise [2]. The theoretical models allow predicting and managing the real object. There are two types of models that are used to predict and analysis the aircraft noise in order to propose technology to reduce the impact of aircraft noise. The theoretical models of the first group are based on empirical data and use specialized software products $[3,4]$. This work is focused on the second type of models that use the basic principles of aircraft modelling. They represent the aircraft as a point-mass model including the aerodynamics of the aircraft itself. The differential equations describe the aircraft position in space and allow finding an appropriate relationship between the investigated parameters. They allow the optimization of aircraft trajectories and determination also of noise level from these trajectories. The models that are used in the literature are with 4 to 6 degrees of freedom [5-7]. Khardi propose a 6-degree of freedom model of aircraft [5] simulating the aircraft departure trajectory in order to minimize aircraft noise levels at reception points around airports. The reduction of noise is achieved by changing the engine thrust. At work [6] an efficient trajectory parameterization for optimization of departure flight paths is described. The aircraft model used in the study has 6-degree of freedom and the noise level is decreased by varying the angle of climb and the thrust setting of the engine. Zhang et al. [7] with aid of 6 degree of freedom mathematical model simulated the aircraft departure trajectory describe that a lower climb speed for the initial acceleration and constant speed climb is preferred for a quieter departure. Paolo et al. [8] propose a simple model for predicting aircraft noise in a given reference point and taking into account some specific operational characteristics that have effect on noise impact on the ground. The model of Stone [9] is widely used in the literature to calculate the engine noise. This is a semi-empirical model which predicts the jet engine noise level for single and mixed dual jets up to bypass ratios of 15 as the main source. In general, the model can be applied to subsonic or supersonic flights up to Mach numbers of 2.5. J. E. Bridges et al. [10] an alyse the method and prove its applicability to modern engines with a high bypass ratio.

A mathematical model with 4 degree of freedom created in Matlab is described in the current work. It includes two sections: modelling the aircraft departure trajectory (take-off and climb), and modelling the engine jet noise level. The goal is to provide a simple model for calculating the engine jet noise levels from these trajectories in a given reference point. The model permits to develop an easy way to find flight operational parameters that effect on aircraft noise levels on the airports such as aircraft groundspeed and weight, and the angle of climb. 


\section{Methodolody}

\section{Data secelction for aircraft trakectory modelling}

For the simulation an aircraft similar to the Airbus A320 is chosen, which is widely used for short to medium range flights [11]. The aircraft is equipped by CFM565A engine. This engine develops a maximum thrust force of $112 \mathrm{kN}$. According to performance training manual of Airbus [12] the aircraft take-off velocity varies as function of the aircraft weight, the airport elevation, the ambient conditions and it is limited by the tire maximum velocity. The take-off is supposed to be performed with CONF1+F flaps/slats configuration. In Tab. 1 is shown the selected parameters: the geometry of the aircraft and its engine, the runway elevation.

Table 1. Aircraft take-off trajectory modelling data

\begin{tabular}{|c|c|c|c|}
\hline Data from & Parameter & Value & Unit \\
\hline \multirow{4}{*}{ Aircraft } & Wing span, $b$ & 35.8 & $\mathrm{~m}$ \\
\cline { 2 - 4 } & Wing are, $S$ & 122.6 & $\mathrm{~m}^{2}$ \\
\cline { 2 - 4 } & Wing aspect ratio, $A$ & 9.395 & - \\
\cline { 2 - 4 } & Sweeper angle, $\chi$ & 25 & degree \\
\hline \multirow{2}{*}{ Runway } & Runway elevation, $h_{\text {runway }}$ & 498 & $\mathrm{~m}$ \\
\cline { 2 - 4 } & Coefficient of rolling resistance, $\mu$ & 0.03 & - \\
\hline \multirow{2}{*}{ Engine } & Thrust, $T$ & 112000 & $\mathrm{~N}$ \\
\cline { 2 - 4 } & Thrust specific fuel consumption, $t s f c$ & $9.4444 \mathrm{e}-005$ & $\mathrm{~N} / \mathrm{sN}$ \\
\hline
\end{tabular}

The international airport of Munich is selected as a baseline airport. The airport is located around $30 \mathrm{~km}$ away from the Munich city centre. The airport consists of two runways and it is one of the ten busiest airports in Europe. Information about the track data and flight performances is provided by the aircraft noise and flight track monitoring system of the airport [13]. The noise monitoring network consists of 16 stationary measuring stations which are positioned at a radius of $20 \mathrm{~km}$ around the airport. Additionally, three mobile measurement stations are also used at places where no stationary measuring station provides information about aircraft noise pollution.

\section{Data secelction for jet engine noise modelling}

The engine jet noise model requires input data with respect to geometry and operational conditions of the engine (Table 2). From the Airbus technical data are taken the geometric parameters [11]. The aircraft altitude, aircraft velocity and the engine thrust setting determine the engine operation. According to the engine operation, specific engine thermodynamic parameters have to be generated. To calculate the parameters of ambient condition it has been used the International 
Standard Atmosphere (ISA) [15]. The required specific design parameter of the engine for primary and secondary flow such as density, temperature and velocity of the jet a turbofan calculator is used [16].

Table 2. Engine noise modelling data

\begin{tabular}{|c|c|c|c|}
\hline Data from & Parameter & Value & Units \\
\hline \multirow{4}{*}{ Engine } & Hydraulic diameter of inner contour, $D_{19}$ & 1.2 & $\mathrm{~m}$ \\
\cline { 2 - 4 } & Hydraulic diameter of outer contour, $D_{9}$ & 1.8 & $\mathrm{~m}$ \\
\cline { 2 - 4 } & Nozzle area of inner contour, $A_{19}$ & Function of $D_{19}$ & $\mathrm{~m}^{2}$ \\
\cline { 2 - 4 } & Nozzle area of outer contour, $A_{9}$ & Function of $D_{9}$ & $\mathrm{~m}^{2}$ \\
\cline { 2 - 4 } & Polar angle, $\alpha^{*}$ & 45 & degree \\
\cline { 2 - 4 } & Jet velocity in inner contour, $v_{9}$ & Vary & $\mathrm{m} / \mathrm{s}$ \\
\cline { 2 - 4 } & Flow velocity in outer contour, $v_{19}$ & Vary & $\mathrm{m} / \mathrm{s}$ \\
\cline { 2 - 4 } & Jet Temperature in inner contour, $T_{9}$ & Vary & $\mathrm{K}$ \\
\cline { 2 - 4 } & Flow Temperature in outer contour, $T_{19}$ & Vary & $\mathrm{K}$ \\
\hline \multirow{4}{*}{$\begin{array}{c}\text { Ambien } \\
\text { condition }\end{array}$} & Air pressure, $p_{\infty}$ & 90811.7 & $\mathrm{~Pa}$ \\
\cline { 2 - 4 } & Air Temperature, $T_{\infty}$ & 284.913 & $\mathrm{~K}$ \\
\cline { 2 - 4 } & Air density, $\rho_{\infty}$ & 1.167 & $\mathrm{~kg} / \mathrm{m}^{3}$ \\
\cline { 2 - 4 } & Air speed, $c_{\infty}$ & 338.377 & $\mathrm{~m} / \mathrm{s}$ \\
\cline { 2 - 4 } & Mach number, $M$ & Vary & - \\
\hline
\end{tabular}

The subscripts 9, 19 correspond to the primary and secondary flow parameters.

\section{Modelling of aircraft departure trajectory and jet engine noise}

In order to calculate the noise level a mathematical model simulated the aircraft departure trajectory is developed. The aircraft departure trajectory includes two sections: take-off and climb trajectory. Fig.1 shows the aircraft used during the take-off modelling in which $\mathrm{R}$ is zero in the air.

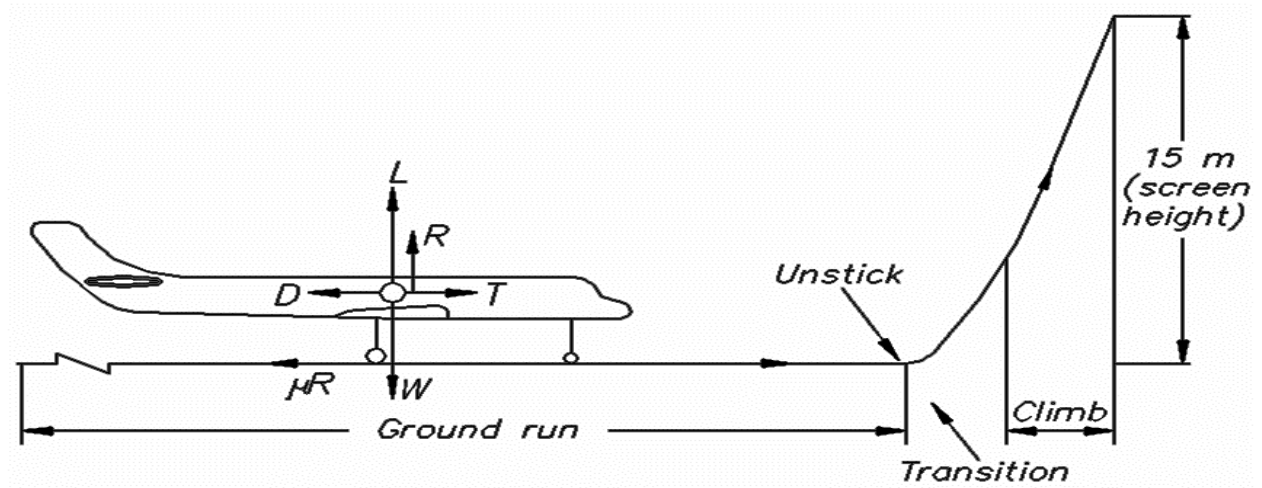

Fig. 1. Aircraft take-off trajectory 


\section{Modeling of aircraft departure trajectory}

For the present scope the aircraft is modelled as a rigid body with varying mass, aerodynamics, thrust and gravitational forces. Some assumtions are made to simplify the problem:

- all forces acting on the aircraft through its centre of gravity;

- no slideslip;

- small angle of attack;

- no wind present;

- the earth is flat and nonrotating.

Therefore, the equations of motion can be expressed as:

For the take-off configuration in the horizontal plane (1) and in the vertical plane are (2):
1) $\quad \stackrel{\square}{\mathrm{V}}=\frac{\mathrm{T}-\mathrm{D}-\mu \mathrm{R}}{\mathrm{m}}$
2) $\quad 0=\mathrm{L}-\mathrm{R}-\mathrm{W}$

For the climb trajectory (3):

3)

$$
\begin{aligned}
& \dot{\mathrm{x}}=\mathrm{V} \cos \gamma \\
& \dot{\mathrm{h}}=\mathrm{V} \sin \gamma
\end{aligned}
$$

$$
\begin{aligned}
& \dot{\mathrm{V}}=\frac{\mathrm{T}-\mathrm{D}}{\mathrm{m}}-\mathrm{g} \sin \gamma \\
& \dot{\gamma}=\frac{(\mathrm{T} \sin \alpha+\mathrm{L})}{\mathrm{mV}}-\frac{\mathrm{g} \cos \gamma}{\mathrm{V}}
\end{aligned}
$$

where $(x, h)$ are the position of the aircraft, $(V, \gamma)$ are respectively the velocity and the angle of the climb. The variables ( $T$, tsf $c, D, R, \mu R, m$ and $g$ ) are respectively the engine thrust, thrust specific fuel consummation, the drag force, the resultant vertical force with respect to the aircraft weight and wing lift, the rolling friction, the aircraft weight and gravity acceleration. Those variables are expressed as: 
4)

$$
\mathrm{T}=\mathrm{T}_{0} \delta_{x} \frac{\rho}{\rho_{0}}\left(1-\mathrm{M}+\frac{\mathrm{M}^{2}}{2}\right)
$$

$$
\begin{aligned}
& \mathrm{D}=\frac{1}{2} \rho \mathrm{SV}^{2}\left(\mathrm{C}_{\mathrm{x} 0}+\mathrm{k}_{\mathrm{i}} \mathrm{C}_{\mathrm{Z} \alpha}^{2} \alpha^{2}\right) \\
& \mathrm{M}=\frac{\mathrm{V}}{\mathrm{c}}
\end{aligned}
$$

with $T_{0}$ the full thrust, $\delta_{x}$ the throttle setting, $\rho$ the density of air at altitude, $\rho_{0}$ the density of air at ground, $M$ the Mach number, $S$ the wing span, $C_{Z \alpha}$ the gradient of the lift depends on the high lift device, $C_{x 0}$ the drag coefficient for $\alpha=0, \mathrm{k}_{\mathrm{i}}$ the induced drag coefficient, $c$ the speed of sound at the altitude $h$ [17].

\section{Modelling of aircraft engine jet noise}

The ground noise levels on airports depend of many variables such as meteorological and runway characteristics, topographic conditions in the airport locations, etc. During the take-off phase, one of the main predominated aircraft noise sources is the jet noise. To model the aircraft engine jet noise in ths work is used a semi-empire model of Stone [9]. The model estimates the noise as a function of the exit velocity, pressure and temperature of the engine outflow. The model assumes a symmetric noise emission with respect to the engine reference axis.

5)

$$
\begin{aligned}
& \mathrm{L}_{\text {jet }}=\mathrm{L}_{\text {norm }}+\Delta \mathrm{L}_{\text {dir/spec }}\left(\operatorname{Str}_{\text {c-jet }}, \alpha_{\text {cor }}^{*}\right)+\Delta \mathrm{L}_{\text {c-jet }} \\
& \mathrm{L}_{\text {norm }} \text { is a normalized sound pressure level and it is defined according to }
\end{aligned}
$$
the atmospheric conditions, the nozzle shape and the operating conditions of the engine:

$$
\mathrm{L}_{\text {norm }}=141.0+10 \log 10\left[\left(\frac{\rho_{\infty}}{\rho_{\infty, \mathrm{ISA}}}\right)^{2}\left(\frac{c_{\infty}}{c_{\infty, \mathrm{ISA}}}\right)^{2}\right]+10 \log 10\left(\frac{\mathrm{A}_{9}}{\mathrm{~d}}\right)+
$$

6)

$$
\begin{aligned}
& +75 \log 10\left(\frac{\overline{\mathrm{v}_{9}}}{\mathrm{c}_{\infty}}\right)-15 \log 10\left[\left(1+\mathrm{M} a_{\mathrm{con}} \cos \left(\alpha^{*}\right)\right)^{2}+0.04 \mathrm{M} a_{\mathrm{con}}^{2}\right]- \\
& -10 \log 10\left[1-\mathrm{M} a \cos \left(\alpha^{*}\right)\right]+3 \log 10\left(\frac{2 \mathrm{~A}_{9}}{\pi\left(\mathrm{D}_{9}\right)^{2}}+0.5\right)
\end{aligned}
$$

where $\overline{\mathrm{v}_{9}}$ is the effective jet speed defined as function of the jet exhaust velocity and aircraft velocity: 
7) $\overline{\mathrm{v}_{9}}=\mathrm{v}_{9}\left[1-\frac{\mathrm{V}}{\mathrm{v}_{9}} \cos \left(\alpha^{*}\right)\right]^{\frac{2}{3}}$

$\omega$ is the density exponent applying to hot jets as function of the effective jet speed and the ambient speed of sound:

8)

$$
\omega=\frac{3.0\left(\overline{\mathrm{v}_{9}} / \mathrm{c}_{\infty}\right)^{3.5}}{0.6+\left(\overline{\mathrm{v}_{9}} / \mathrm{c}_{\infty}\right)^{3.5}}-1
$$

$\mathrm{M} a_{\text {con }}$ is a convective Mach number and it is defined as function of aircraft velocity, jet exhaust velocity, the ambient speed of sound and the polar angle:

9)

$$
\mathrm{M} a_{\text {con }}=0.62 \frac{\mathrm{v}_{9}-\mathrm{V} \cos \left(\alpha^{*}\right)}{\mathrm{c}_{\infty}}
$$

$\mathrm{Str}_{9}$ is an effective Strouhal number.

$$
\operatorname{Str}_{9}=\mathrm{f} \frac{\sqrt{4 \mathrm{~A}_{9} / \pi}}{\overline{\mathrm{v}_{9}}}\left(\frac{\mathrm{D}_{9}}{\sqrt{4 \mathrm{~A}_{9} / \pi}}\right)^{0.4}\left(\frac{\mathrm{T}_{\mathrm{t}, 9}}{\mathrm{~T}_{\mathrm{t}, \infty}}\right)^{0.4\left[\left(1+\cos \left(\alpha_{\mathrm{cor}}^{*}\right)\right)\right]}\left(1-\mathrm{M} a \cos \left(\alpha^{*}\right)\right)
$$

10)

$$
\left[\frac{\left(1+0.62\left(\frac{\mathrm{v}_{9}-\mathrm{v}_{\infty}}{\mathrm{c}_{\infty}}\right) \cos \left(\alpha^{*}\right)\right)^{2}+0.01538\left(\frac{\mathrm{v}_{9}-\mathrm{v}_{\infty}}{\mathrm{c}_{\infty}}\right)^{2}}{\left(1+0.62\left(\frac{\mathrm{v}_{9}}{\mathrm{c}_{\infty}}\right) \cos \left(\alpha^{*}\right)\right)^{2}+0.01538\left(\frac{\mathrm{v}_{9}}{\mathrm{c}_{\infty}}\right)^{2}}\right]^{0.5}
$$

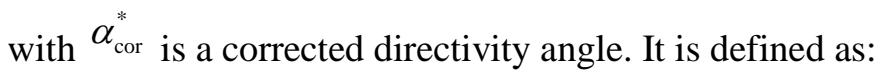

11)

12)

$$
\begin{aligned}
& \mathrm{M} a_{\mathrm{con}}=0.62 \frac{\mathrm{v}_{9}-\mathrm{V} \cos \left(\alpha^{*}\right)}{\mathrm{c}_{\infty}} \\
& \alpha_{\text {cor }}^{*}=\alpha^{*}\left(\mathrm{v}_{9} / \mathrm{c}_{\infty}\right)^{0.1}
\end{aligned}
$$

$\Delta \mathrm{L}_{\text {c-jet }}$ is defined as 


$$
\Delta \mathrm{L}_{\mathrm{c} \text {.jet }}=5 \log 10\left(\frac{\mathrm{T}_{t, 9}}{\mathrm{~T}_{t, 19}}\right)+10 \log 10\left[\left(1-\frac{\mathrm{v}_{19}}{\mathrm{v}_{9}}\right)^{\mathrm{m}}+1.2\left(\frac{1+\left(\frac{\mathrm{A}_{19}}{\mathrm{~A}_{9}} \frac{\mathrm{v}_{19}^{2}}{\mathrm{v}_{9}^{2}}\right)^{4}}{\left(1+\frac{\mathrm{A}_{19}}{\mathrm{~A}_{9}}\right)^{3}}\right)\right]
$$

where the exponent $m$ is defined as a function of the area ratio:

$$
\mathrm{m}= \begin{cases}1.1 \sqrt{\mathrm{A}_{19} / \mathrm{A}_{9}} & \text { for } \mathrm{A}_{19} / \mathrm{A}_{9}<29.7 \\ 6.0 & \text { for } \mathrm{A}_{19} / \mathrm{A}_{9}>29.7\end{cases}
$$

\section{Results and discussion}

To study the affect of the flight operational parameters on the jet noise levels, it was simulated different aircraft trajectories based on the Airbus A320 at Munich airport (Fig. 2). The parameters used in the simulations are listed in Table 1 and 2. The simulated departure trajectory was based on a Standart Instrumental Departure [14] and the calculation of the jet engine noise levels was made for 2 points from that trajectory - during the take-off and during the climb. The results regarding the noise levels were compared with the experimental data published by the aircraft noise and flight track monitoring system at Munich airport [13]. There are presented in Table 3 and 4.

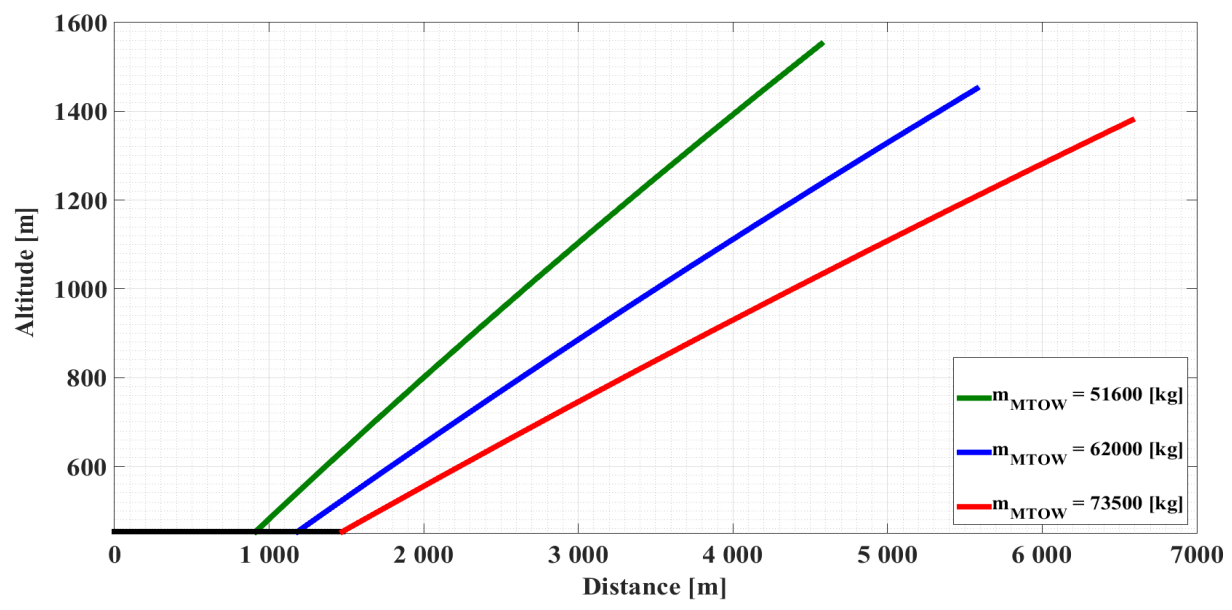

Fig. 2. Aircraft departure trajectory 
Table 3. Obtained numerical value from aircraft trajectory

\begin{tabular}{|c|c|c|c|c|}
\hline Parameter & \multicolumn{3}{|c|}{ Value } & Unit \\
\hline Weight & 51600 & 62000 & 73500 & $\mathrm{~kg}$ \\
\hline $\mathrm{V}_{\text {LOF }}$ & 55 & 65 & 75 & $\mathrm{~m} / \mathrm{s}$ \\
\hline Time of take-off & 31 & 33 & 35 & $\mathrm{~s}$ \\
\hline Take-off ground run distance & 913 & 1184 & 1474 & $\mathrm{~m}$ \\
\hline $\mathrm{V}_{\text {CLIMB }}$ & 90 & 100 & 110 & $\mathrm{~m} / \mathrm{s}$ \\
\hline Climb altitude, $\mathrm{h}_{\text {CLIMB }}$ & 1552 & 1451 & 1380 & $\mathrm{~m}$ \\
\hline Time of climb, $\mathrm{t}_{\text {CLIMB }}$ & 65 & 65 & 65 & $\mathrm{~s}$ \\
\hline Angle of climb, $\gamma$ & 15.36 & 11.82 & 9.52 & degree \\
\hline
\end{tabular}

Table 4. Obtained numerical value from the jet engine model

\begin{tabular}{|c|c|c|c|c|}
\hline Parameter & \multicolumn{3}{|c|}{ Value } & Unit \\
\hline Weight & 51600 & 62000 & 73500 & $\mathrm{~kg}$ \\
\hline Noise level on the runway & 63 & 68 & 72 & $\mathrm{~dB}$ \\
\hline Noise level on the altitude & 70 & 73 & 75 & $\mathrm{~dB}$ \\
\hline
\end{tabular}

According to the model:

- on the runway, at minimum take-off weight $m_{\text {MTOW }}=51600 \mathrm{~kg}$ and aircraft groundspeed $V_{L O F}=55 \mathrm{~m} / \mathrm{s}$, the obtained level of jet engine noise is $63 \mathrm{~dB}$;

- on the runway, at nominal take-off weight $m_{\text {MTоW }}=62000 \mathrm{~kg}$ and aircraft groundspeed $V_{L O F}=65 \mathrm{~m} / \mathrm{s}$, the noise level from the jet engine increases up to $68 \mathrm{~dB}$;

- on the runway, at maximum take-off weight $m_{M T O W}=73500 \mathrm{~kg}$ and aircraft groundspeed $V_{L O F}=75 \mathrm{~m} / \mathrm{s}$, the noise level from the jet engine continues to increase up to $72 \mathrm{~dB}$;

- on the initial climb with velocity $V_{\text {CLIMB }}=90 \mathrm{~m} / \mathrm{s}$ and minimum aircraft weight $m_{\text {Мто }}=51600 \mathrm{~kg}$, the noise level from the jet engine is $70 \mathrm{~dB}$;

- on the initial climb with velocity $V_{\text {СLIMB }}=100 \mathrm{~m} / \mathrm{s}$ and nominal aircraft weight $m_{\text {мтош }}=62000 \mathrm{~kg}$, the noise level from the jet engine increase up to $73 \mathrm{~dB}$;

- on the initial climb with velocity $V_{\text {CLIMB }}=110 \mathrm{~m} / \mathrm{s}$ and maximum aircraft weight $m_{\text {Мто }}=73500 \mathrm{~kg}$, the noise level from the jet engine continues to increase up to $75 \mathrm{~dB}$.

The results of this work show that the engine jet noise levels are most affected by the actual take-off weight and the groundspeed reached by aircraft during the take-off and the inicial climb phase (Table 3 and 4). It can be noted that 
aircraft noise level is directly proportional to the take-off weight (Table 3): heavier aircraft must increase engine thrust in order to reach the minimum speed for takeoff. During departure as the engine is the main noise source this action leads to an increase in engine noise levels. It can also be obseved that noise is directly proportional to the aircraft groundspeed (Table 3). These variables are affected by adopted pilot technique. Analyzing the lowest and highest values of the take-off ground run distances that correspond to the lowest and highest values of the noise level it can be supposed that aircraft covers longer disnance on the ground reaches lower altitude during the climb with larger ground speed deteriorets the noise impact.

It was also able to use the experimental data from two noise monitoring stations (located at the airport and Pulling) for a real departure procedure of A320 from runway 08L/26R at Munich airport. The measured and calculated noise level, which are presented in Table 4 and Fig. 3 and 4, differ by $0.1 \mathrm{~dB}$ at the airport station and $1.8 \mathrm{~dB}$ at Pulling station. These results show that the model that was developed can be used with some confidence to predict noise level from aircraft in the vicinity of airports.

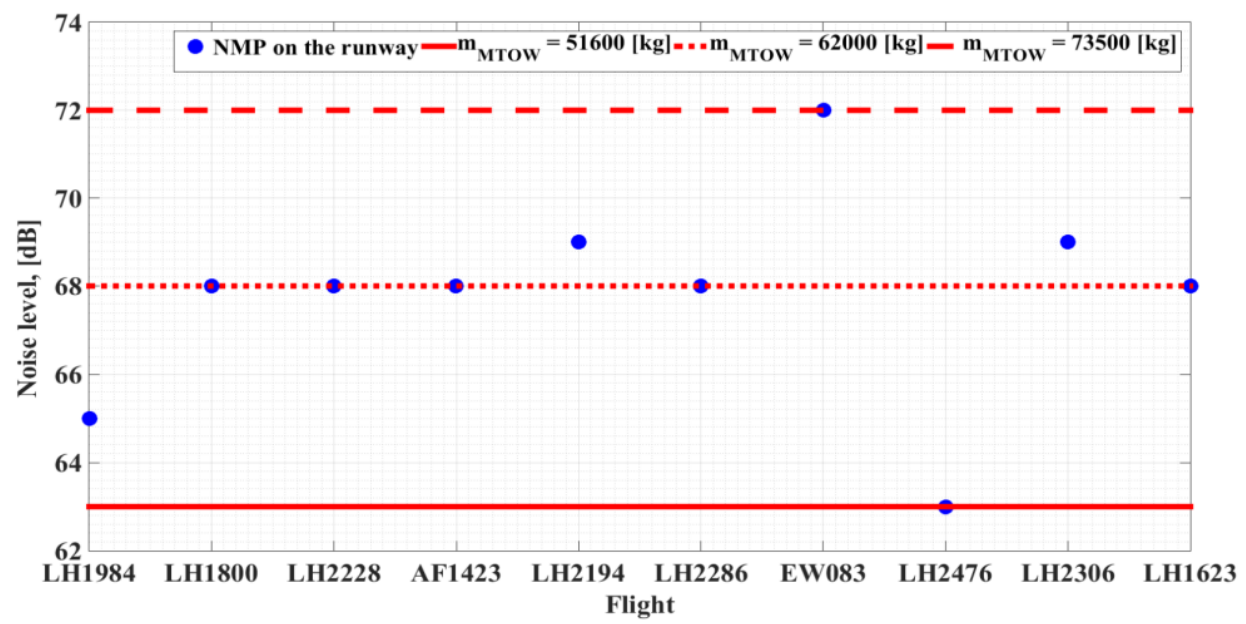

Fig. 3. Obtained results from the engine noise model and the real flight from the airport noise monitoring system, NMP on the runway 


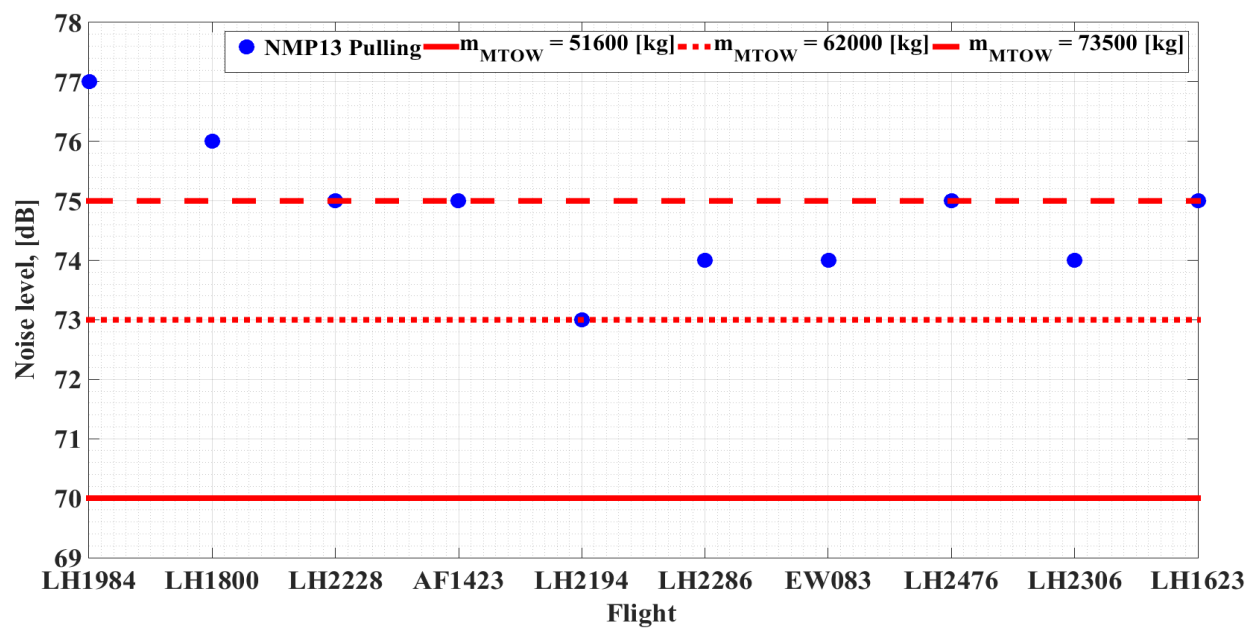

Fig. 4. Obtained results from the engine noise model and the real flight from the airport noise monitoring system, NMP 13 Pullin

Table 4. Data from the measurement stations at Munich airport runway 08L/26R on 29.04.2019 for the day period between 08:00 and 17:00

\begin{tabular}{|c|c|c|c|c|c|c|}
\hline \multirow[b]{2}{*}{ № } & \multirow{2}{*}{\multicolumn{2}{|c|}{ Flight }} & \multirow{2}{*}{$\begin{array}{l}\mathbf{V}_{\text {LOF, }} \\
{[\mathrm{m} / \mathrm{s}]}\end{array}$} & \multirow{2}{*}{$\begin{array}{c}\text { tLOF }_{\text {, }} \\
{[\mathrm{s}]}\end{array}$} & \multicolumn{2}{|c|}{ Noise, [dB] } \\
\hline & & & & & NMP0 & NMP13 \\
\hline 1 & Munich-Cologne & LH1984 & 75 & 35 & 65 & 77 \\
\hline 2 & Munich-Madrid & LH1800 & 80 & 28 & 68 & 76 \\
\hline 3 & Munich-Paris & LH2228 & 75 & 36 & 68 & 75 \\
\hline 4 & Munich-Paris & AF1423 & 75 & 34 & 68 & 75 \\
\hline 5 & Munich-Berlin & LH2194 & 80 & 32 & 69 & 73 \\
\hline 6 & Munich-Brussels & LH2286 & 75 & 36 & 68 & 74 \\
\hline 7 & Munich-Cologne & EW083 & 75 & 40 & 72 & 74 \\
\hline 8 & Munich-London & LH2476 & 75 & 30 & 63 & 75 \\
\hline 9 & Munich-Amsterdam & LH2306 & 80 & 38 & 69 & 74 \\
\hline 10 & Munich-Paris & LH1623 & 75 & 35 & 68 & 75 \\
\hline
\end{tabular}

\section{Conclusion}

Aircraft noise is one the most detrimental environmental effect of aviation. The impacts of aircraft noise on people living in the vicinity of airports cannot be overestimated. In some airports, noise constrains air traffic growth. The main source of the aircraft noise during departure is assumed to be from its engine. In the current work is created a mathematical model simulated the aircraft departure 
trajecrory (take-off and climb). The jet engine noise level from these trajectories is calculated. The trajectory model and the jet engine noise model are validated and demonstrate a correct physical behaviour. The suggested model could be integrated into noise-reduction measures that should take into account the interaction between the flight operation parameters and noise leves for a careful air traffic planning

In the future, the research will focus on:

- including the atmospheric factors in the trajectory model because of their non-negligible roles in flight performance during the take-off;

- creating a model to investigate the possibility of trajectory optimization during the departure trajectory in order to decrease the engine noise level.

\section{Acknowledgments}

This work has been supported by Research and Scientific Centre of Technical University of Sofia (Grant № 181ПP0012-04).

\section{References}

1. Eurocontrol. 2019, European Aviation Environmental Report 2019, ISBN 978-92-9210214-2.

2. Futuresky. http://www.futuresky.eu/projects/noise (Accessed on 31.05.2019).

3. Boeker, E. R., E. Dinges, B. He, G, Fleming, C. J. Roof, P. J. Gerbi, A. S. Rapoza, and J. Hermann, Integrated noise model (INM) version 7.0 technical manual, FAAAEE-08-01, 2008.

4. Krebs, W., Sound source data for aircraft noise simulation, Acta Acoustica united with Acustica, 2004, 91-100, 90p.

5. Khardi, S., Mathematical Model for Advanced CDA and Takeoff Procedures Minimizing Aircrft Environmental Impact, International Mathematical Forum, 2010, 5, 36, 1747-74.

6. Hartjes, S. and H. G. Visser, Efficient trajectory parameterization for environmental optimization of departure flight paths using a genetic algorithm, Journal of Aerospace Engineering, https://doi.org/10.1177/0954410016648980.

7. Zhang, M., A. Filippone; N. Bojdo. Using Trajectory Optimization to Minimize Aircraft Noise Impact, Inter.Noise, 27-30 August 2017, Honk Kong.

8. Gagliardi, P., L. Teti, and G. Licitra, A statistical evaluation on flight operational characteristics affecting aircraft noise during take-off, Applied Acoustics, 2018, $134,8-15$.

9. Stone, J. R., D. E. Groesbeck, and C. L. Zola, Conventional profile coaxial jet noise prediction, AIAA Journal, 1983, 21(1), 336-42.

10. Bridges, J. E., A. Khavaran, and C.A. Hunter, Assessment of Current Jet Noise Prediction Capabilities, 14th Aeroacoustics Conference, Vancouver, British Columbia, Canada, May 5-7, 2008. 
11. Airbus-AC-A320, Aircraft Characteristics - Airport and Maintenance Planning. AIRBUS S.A.S. Customer Services, Technical Data Support and Services, 31707 Blagnac Cedex, FRANCE, 2016.

12. Airbus, Training \& Flight Operation support and services, Flight crew performance course, A318/A319/A320/A321, Performance Training Manual, 31707 Blagnac Cedex, FRANCE, 2005.

13. https://travis-web01.munichairport.de/data/travis.php?lang=en\&_ga=2.41081378.185368683.15245778722134088401.1513440516 (Accessed at 31.05.2019).

14.EDDM. Muenchen Airport. https://skyvector.com/airport/EDDM/Muenchen-Airport (Accessed on 31.05.2019).

15.1976 Standard Atmosphere Calculator. https://www.digitaldutch.com/atmoscalc/ (Accessed on 31.05.2019).

16. Turbofan Calculator. PIC-C. https://www.particleincell.com/2014/turbofan-calculator/ (Accessed on 31.05.2019).

17. Bos, Aircraft performance summary tables for the base of aircraft data (BADA) revision 3.0. EEC Technical / Scientific Reports.

\section{РАСЧЕТ УРОВНЯ ШУМА ВОЗДУШНОГО СУДНА ПРИ ВЗЛЕТЕ}

\section{Х. Георгиева}

\section{Резюме}

В этой статье описана математическая модель с 4 степенями свободы, созданная в Matlab для траектории вылета самолёта. В качестве эталонного самолёта был выбран коммерческий пассажирский самолёт среднего размера, подобный Airbus A320. Самолет представлен как твёрдое тело. Параметры модели получены из сайтов Airbus, а моделируемая траектория вылета в аэропорту Мюнхена, основана на стандартном инструментальном вылете. Для прогнозирования шума струи была использована полуэмпирическая модель Стоуна. Предложенная модель проверена на соответствие 10 реальным полетам, полученным из авиационного шума и системы мониторинга траектории полета в аэропорту Мюнхена. Рассчитывается ошибка между реальными данными и моделирование. Полученные результаты представлены численно и графически. Наблюдаемые эффекты эксплуатационных параметров полёта, влияющие на уровень шума воздушного судна во время взлета, являются предметом обсуждения в документе. 